\title{
Economic Feasibility of Solar Irrigation Pumps: A Study of Northern Bangladesh
}

\author{
Md. Tawhidul Islama, ${ }^{a *}$ and Md. Elias Hossain ${ }^{c}$ \\ aDepartment of Economics, Pabna University of Science and Technology, Bangladesh. \\ ${ }^{b}$ Institute of Bangladesh Studies, University of Rajshahi, Bangladesh. \\ ${ }^{c}$ Department of Economics, University of Rajshahi, Bangladesh.
}

\begin{abstract}
Bangladesh is the most densely populated country in the world. With a total population of around 165 million, the country has constantly been facing food security challenges and other problems. Therefore, increasing food production is one of the feasible solutions to this challenge, and proper agricultural land use for food production bears critical importance. Adopting sustainable irrigation systems and viable technologies would be vital for ensuring efficient use of agricultural land in Bangladesh to safeguard the country's food security. Solar irrigation pumps (SIPs) can be a reliable option in this regard. However, Bangladesh has experienced a prolonged growth rate of SIP installation in the last decade. The country has set a target to install 10000 SIPs by the year 2027, albeit it is a tiny share of the 1.57 million conventional irrigation pumps operating in the country. This study aims to investigate the economic feasibility of the SIPs operating in the northern region of Bangladesh in terms of estimating financial feasibility and environmental benefits. The study is mainly based on primary data collected from the users of SIPs from two Upazilas of Dinajpur and Rangpur districts. A total of 14 SIPs, categorized into large, medium, and small pumps, are selected randomly from the available SIPs in the study areas. The financial analysis reveals that small SIPs are the most profitable option (20\% IRR) for investment. Large SIPs are moderately profitable (10\% IRR), and their profitability can be improved (10.50\% IRR) by introducing additional uses of solar energy. However, medium SIPs are the worst (5\% IRR) option for investment. In the study areas, large and medium SIPs are designed for the 'fees for service model', and small SIPs are designed for the 'fees for ownership model'. It is found that the 'fees for ownership model' is more profitable than the 'fees for service model'. Moreover, the net environmental benefit for all SIPs is found almost equal to the given subsidy for installing them. Also, the net environmental benefit per kilowatt peak (kWp) is highest for the small SIPs. This paper recommends that additional use (e.g., husking, grinding, supply excess electricity to grid, and so on) of solar energy can improve the profitability of investment on SIPs. Further, the government should continue giving grants for installing SIPs and promote 'fees for ownership model' (small SIPs) for personal use. It would speed up the dissemination rate of SIPs and help increase the country's agricultural production and improve the environmental conditions.
\end{abstract}

Keywords: Economic Feasibility, Environmental Benefit, Internal Rate of Return, Northern Bangladesh, Solar Irrigation Pump (SIP)

Article History: Received: 19th May 2021; Revised: $8^{\text {th }}$ July 2021; Accepted: 21 st July 2021; Available online: $25^{\text {th }}$ August 2021

How to Cite This Article: Islam, M.T. and Hossain, M.E. (2022) Economic Feasibility of Solar Irrigation Pumps: A Study of Northern Bangladesh. International Journal of Renewable Energy Development, 11(1), 1-13.

https://doi.org/10.14710/ijred.2022.38469

\section{Introduction}

Bangladesh is a developing country in the South Asian region with a total population of around 165 million. The country is the most densely populated one in the world, with 1132 persons per square kilometre in 2019 (World Bank, 2019). The population of the country has been increasing at a moderate growth rate, and under the medium variant fertility assumption, the total population of Bangladesh would be about 191 million in 2031, 216 million in 2051, and 223 million in 2061 (BBS, 2015). Thus, the country will face the problems associated with a growing population in the coming decades. It will be challenging to ensure food security for this growing population. This will require the country to increase food production by using improved and sustainable technology in agriculture. The adoption of suitable irrigation can increase the cropping intensity and productivity of the cultivable land in Bangladesh. The total cultivable land in the country is 8.52 million hectares, of which the total cropped area is 14.943 million hectares (Division, 2008). Out of the 8.52 million hectares of cultivable land, about 7.76 million hectares of land has already come under irrigation facility (Division, 2008). In the earlier days, surface water from rivers, canals, etc., was the source of irrigation. However, nowadays, many rivers suffer from the insufficiency of water, especially in the dry seasons. As a result, underground water has become the primary source of irrigation. Farmers mainly use diesel and electricity-run pumps for irrigation. Over 1.57 million irrigation pumps are operating in the country, of which $80 \%$ are diesel and $20 \%$ are electricity operated (BADC,

\footnotetext{
* Corresponding author: tawhideco@pust.ac.bd
} 
2020). Most pumps are diesel-run because electricity from the national grid is unavailable in remote agricultural fields. Therefore, every year, Bangladesh has to import about 1.06 million tons of diesel (BADC, 2020). The government usually makes diesel affordable for irrigation by providing subsidies, which creates extra pressure on the economy. In this situation, SIPs can be an economic saviour for the country. For example, 1300 solar irrigation pumps (SIPs) can save about $\$ 3.2$ million annually by replacing diesel with clean and renewable solar energy (BADC, 2020).

On the other hand, the grid-connected irrigation pumps also have some problems in Bangladesh due to low voltage and frequent electricity cut-off problems. Bangladesh faces an acute energy crisis of $1248 \mathrm{MW}$ (BBS, 2019), especially in the peak irrigation period. The total electricity generation capacity of the country was about $15000 \mathrm{MW}$ in 2018. However, the maximum generation was 10958 MW due to fuel supply constraints (BBS, 2019). Bangladesh's primary sources of electricity generation are natural gas and oil, which generate $61.37 \%$ and $24.72 \%$ of the country's total power, respectively (BBS, 2019). Due to the country's reducing reserve of natural gas and oil price volatility in the international market, these sources have become non-sustainable and vulnerable. Thus, the government has fixed a target to generate $20 \%$ of its total power by renewable energy sources by 2030 (BPDB, 2020). It also has a target to generate at least $150 \mathrm{MW}$ electricity from SIPs by 2020 (SREDA, 2020). It would be possible because solar radiation is amply available in Bangladesh, with average radiation between 4 and $6.5 \mathrm{~kW} / \mathrm{m} 2 /$ day (Hossain et al., 2015). The maximum solar insolation occurs from February to June, and the minimum occurs from October to February. The average bright sunshine hours vary from 6 to $9 \mathrm{~h} /$ day, which is one of the preconditions for SIPs' viability (Islam et al., 2008).

Besides, the $\mathrm{CO}_{2}$ emission from the irrigation pumps in Bangladesh's agriculture sector increases day by day. It increased to 7814 thousand tons in 2012 from 705 thousand tons in 1983, an almost 11-fold increase in $\mathrm{CO}_{2}$ emission from diesel and electricity run irrigation pumps within 30 years (Al-Masum et al., 2017). SIPs' introduction instead of conventional pumps can prevent the emission. However, the environmental benefit of SIP in monetary terms is not yet measured in Bangladesh.

Again, Bangladesh experienced a prolonged growth rate of the SIPs. According to the Sustainable and Renewable Energy Development Authority (SREDA), the total generated power from the approved SIPs is about 13.90MW, which was targeted to be about 150MW (SREDA, 2020). Infrastructure Development Company Limited (IDCOL), the responsible authority for SIPs dissemination in Bangladesh, revised the installation target of SIPs at 10000 within 2027, which was 50000 within 2025 (IDCOL, 2021).

Thus, the business model for the SIPs dissemination may not work efficiently in Bangladesh. According to the finding of Agrawal and Jain, different countries adopt different business models for SIPs spreading. Almost all business models ensure an individual or group of farmers is the owner of SIP. However, according to the 'water as a service model' (shown in Figure 1), NGOs or MFIs are the installers, owners, and caretakers of the SIPs throughout their whole lifespan (20-25 years) (Agrawal \& Jain, 2019).
IDCOL, with the help of NGOs, mainly deploy this model in Bangladesh (Agrawal \& Jain, 2019). Under this model, NGOs provide irrigation services for fees to the farmers. Hence, it creates difficulties for the framers to get maximum benefits from the subsidies and loans on the SIPs. As a result, the acceptability of the pumps may not increase rapidly in the country. Also, the capital cost is still the main hindrance to the widespread use of SIPs in developing nations (Meah et al., 2008). Thus, this study tried to measure the financial feasibility and environmental benefit of SIPs in Bangladesh. For this purpose, this paper is organized as follows: Section 2 provides a literature review, Section 3 illustrates key features of SIPs; Section 4 explains the methodology; Section 5 demonstrates basic information of different SIPs; Section 6 provides a discussion of results; and finally, Section 7 presents the conclusion.

\section{Literature Review}

Conventional irrigation pumps' harmful impact on the environment and their sustainability becomes a great concern worldwide since the demand for irrigation increases gradually. Therefore, policymakers of different countries support new policies to replace the conventional pumps with renewable energy-based ones like solar and wind pumps to ensure sustainable water supply for irrigation. It helps to ensure food security by increasing the yield of crops in the long run. It would also help achieve the seventh goal of the SDG to ensure affordable, reliable, sustainable, and modern energy for all within 2030. That is why it would be vital to formulate appropriate policies to accept the new renewable energy technology at the root level. Some researchers measured the financial feasibility and environmental impact of SIPs in this regard.

For example, Kelley et al. found that solar-powered irrigation is economically viable in Saudi Arabia from the lifecycle cost analysis. However, the high costs of solar panels involve a high initial cash outlay, which will need financing (Kelley et al., 2010). In Bangladesh, the initial cost of SIP would also make a barrier for the poor, middle, and even wealthy farmers to adopt this technology. García et al. estimated that the economic payback time was 8.6 years for the off-grid SIP (García et al., 2019). However, in Bangladesh's context, existing studies have not measured PBPs of different SIPs precisely. In Sudan's case, Babkir Ali found that SIPs would contribute significantly to the sustainable development of the agricultural sector in Sudan (Ali, 2018). In Algeria, Hamidat et al. found that SIPs can efficiently pump sufficient water for small-scale irrigation with an area smaller than $2 \mathrm{Ha}$ (Hamidat et al., 2003). In Bangladesh, the average holding is less than 1 ha (BBS, 2018). Thus, the SIP's owner can sell irrigation water to his neighbours and earn from this investment. In India, Pande et al. found that supplying water through a solar pump for drip irrigation to an orchard farm is financially feasible, and the calculated payback period was 6 years (Pande et al., 2003). However, in Bangladesh, mainly flood irrigation is practised for paddy cultivation. Thus, the feasibility test for flood irrigation by SIP would be crucial for this region. Surendra et al. presented the economic analysis of solar pumps for small farmers in India. They found that small capacity pumps are most 
suitable for countries like India (Surendra \& Subbaraman, 2002). However, the SIP's most suitable size was not yet measured for Bangladesh. Purohit and Kandpal presented a financial performance evaluation of a PV water pump in India. They found that PV pumping systems are viable when the government provides sufficient incentives (Purohit \& Kandpal, 2011). Thus, it would be challenging for the investors to manage the capital cost of SIP without subsidy. In Bangladesh, Najmul Hoque et al. also verified the findings of Purohit and Kandpal. According to their estimation, a SIP's average payback period (PBP) was 5.43 years, and IRR was $18 \%$ with the current financial scheme (40\% grant and $40 \%$ soft loan of total price). However, the project was not economically attractive without any support, as the payback period became about 18 years (Hoque et al., 2016).

Moreover, SIPs can reduce greenhouse gas (GHG) emissions by replacing fossil fuels with solar energy for irrigation. Some studies investigated SIPs' potentiality to minimize environmental pollution. According to the Gesellschaft für Internationale Zusammenarbeit (GIZ)'s report in 2020, solar panels, grid electricity, and diesel machines generate 16 to $32 \mathrm{~g}, 600 \mathrm{~g}$, and $1000 \mathrm{~g} \mathrm{CO}_{2}$ gas, respectively, to produce $1 \mathrm{kWh}$ power (Sass \& Hahn, 2020). Thus, it is clear that the solar system is the most environment friendly option to generate power among the three available alternatives. According to the Parliamentary Office of Science and Technology (POST) report, the solar PV system and grid-connected machine generate $75-116 \mathrm{~g}$ and 488-990 $\mathrm{g} \mathrm{CO}_{2}$, respectively, to produce $1 \mathrm{kWh}$ power (Allen, 2011). Therefore, according to this report, solar irrigation is more environment friendly than grid-connected irrigation. Ould-Amrouche et $a l$. found that the solar pump generates almost $0 \mathrm{~g} \mathrm{CO}$ to withdraw $1 \mathrm{~m}^{3}$ or 1000 litre additional water from the underground. On the other hand, diesel machine generates almost 480-2230 g CO 2 (Ould-amrouche et al., 2010). Thus, it is evident that to mitigate $\mathrm{CO}_{2}$ emissions; a solar pump is a better option for irrigation than a diesel pump. Finally, Nikzad et al. in north Iran observed that $\mathrm{CO}_{2}$ production from the off-grid SIP during the project's lifetime is 190-201 times lower than the conventional irrigation pumps (CIPs) (Nikzad et al., 2019). In India, diesel and electric water pumps added almost 45 million tons of $\mathrm{CO}_{2}$ to the atmosphere annually, equivalent to $8 \%$ $12 \%$ of the country's total greenhouse gas emissions (Rathore et al., 2018). Thus, the contribution of CIPs to greenhouse gas emissions would be concerning, especially for agriculture-based countries like India and Bangladesh. However, the SIP can reduce emissions as it is an environment-friendly irrigation technology (Hossain et al., 2015). Nevertheless, the total $\mathrm{CO}_{2}$ emission reduction by SIPs and the monetary gain of this reduction are not well measured in Bangladesh. Some researchers attempted to determine the financial feasibility of SIPs by calculating NPV, IRR, and PBP of an arbitrary SIP. However, no study makes an exact comparison among the SIPs with various capacities. Moreover, estimation of SIP's environmental benefits in monetary terms is rare. It would be helpful to evaluate the given subsidy for installing a SIP in terms of environmental benefits. Thus, this study examined the financial feasibility and environmental benefit of SIPs in Bangladesh based on primary and secondary data collected from the SIPs' users and installers.

\section{Key Features of Solar Irrigation Pump (SIP)}

The inter-connected photovoltaic (PV) or solar panels turn sunlight into direct current (DC), and the electricity is transferred to the solar water pump through a controller. Water delivery of a SIP depends on the installed solar panels' number and the depth of the water. Some SIPs use alternating current (AC), in which an inverter replaces the controller. So, solar panels, submersible pump, controller or inverter, installation materials, tracking structure, and pipe are necessary to install a SIP (VEIPL, 2018). The components of a typical $1.8 \mathrm{kWp}$ SIP are mentioned in Table 1 . Solar panel's cost is a vital part of the total investment for a SIP, covering about $45 \%$ of the total cost. The installation and pump costs account for $18 \%$ and $16 \%$ of the total cost, respectively.

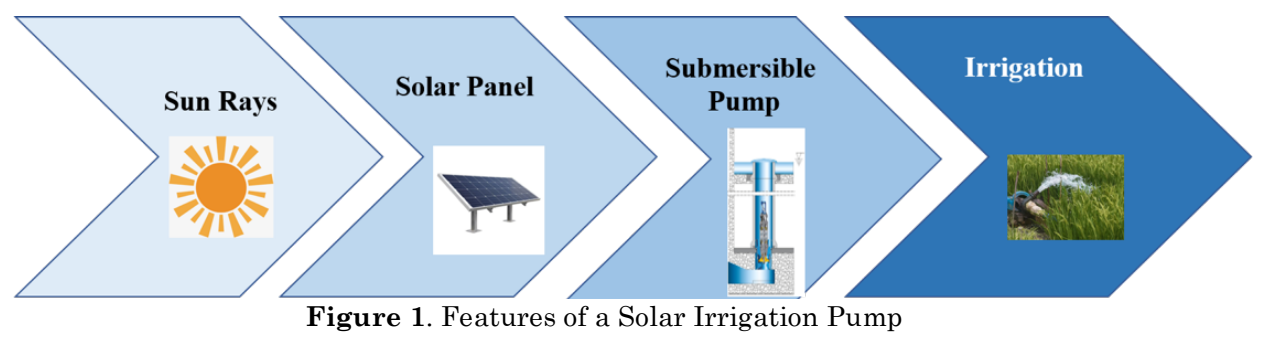

Table 1

System Components of a $1.8 \mathrm{kWp} \mathrm{SIP}$

\begin{tabular}{ccc}
\hline Sr. No. & Description & Quantity \\
\hline 1 & Solar Modules/panels 75 Wp & 24 \\
2 & Array tracking structure & 1 \\
3 & Submersible pump 2 HP & 1 \\
4 & Motor/pump Controller & 1 \\
5 & Installation kit & 1 \\
6 & 2 2" HDPE pipe (meter) & 10 \\
\hline
\end{tabular}

Source: Vatio Energy India Private Limited (2018)(VEIPL, 2018) 


\subsection{Solar Irrigation Pumps (SIPs) in Bangladesh}

The average bright sunshine hours vary from 6 to 9 hours per day in Bangladesh. Thus, solar energy is richly available in the country with a variation of average solar insolation between 4 and $6.5 \mathrm{~kW} / \mathrm{m}^{2} /$ day (Tanvir et al., 2017). IDCOL (Infrastructure Development Company Ltd. $\mathrm{BD})$, the largest financier and monitoring authority in the renewable energy sector in Bangladesh, tries to utilize the available solar energy. It is a government-owned financial institution established in 1997 to encourage private sector participation in infrastructure and renewable energy development projects. IDCOL receives funds from the government of Bangladesh and multiple development partners like the WB (World Bank), KfW (German government-owned development bank), KOICA (Korea International Cooperation Agency), JICA (Japan International Cooperation Agency), ADB (Asian Development Bank), USAID (United States Agency for International Development), GPOBA (Global Partnership of Output-Based Aid) and BCCRF (Bangladesh Climate Change Resilience Fund), and provides the funds as grants and loans to the partner organizations (POs) like Grameen Shakti, Jagorani Energy, Solargao Limited, Rahimafrooz Renewable Energy Ltd., Gazi Renewable Energy Company Ltd., Electro Solar Power Ltd., Bright Green Energy Foundation, Network for Universal Services and Rural Advancement (NUSRA), etc. (IDCOL, 2019). The POs install and maintain the SIPs at the user level.

Grameen Shakti (GS), with the assistance of IDCOL, has installed the country's first SIP in Naogaon in 2010.
IDCOL, with the collaboration of POs, installed 832 SIPs up to 2019 in Bangladesh. Moreover, the total generated power from the 832 installed SIPs is about 13.90MW (Table 2). However, the government initially aimed to generate at least 150MW electricity from SIPs by 2020 and gradually increase the installed capacity by extending the pumps' number to 50000 by 2025 (Division, 2008). The projected number is illustrated year by year in Table 3 .

The projected 50000 SIPs within 2025 will be a minimal share of 1.57 million conventional irrigation pumps (Hossain et al., 2015). Unfortunately, recently IDCOL has revised the target to install only 10000 SIPs within 2027 (IDCOL, 2021).

\subsection{Two Models for Solar Irrigation Pump (SIP) Program}

IDCOL proposed two models, i.e., 'fees for service model' and 'fees for ownership model' for installing and managing SIPs in Bangladesh.

\subsubsection{Fees for Service Model}

In the 'fees for service model', IDCOL provides grants and soft loans to the partner organizations (POs). POs are the several non-governmental organizations (NGOs) and microfinance institutions (MFIs) operated in the country. They collect SIP equipment from suppliers, install them, and sell irrigation water to the farmers. Figure 2 depicts the model.

Table 2

Division-wise Number of SIPs up to 2019

\begin{tabular}{ccc}
\hline Region & Approved & Installed \\
\hline Rangpur & 705 & 574 \\
Rajshahi & 104 & 44 \\
Khulna & 325 & 211 \\
Chittagong & 2 & 2 \\
Dhaka & 4 & 1 \\
Total & 1140 & 832 \\
Capacity in MW & $\mathbf{1 3 . 9 0}$ & $\mathbf{8 . 7 2}$ \\
\hline
\end{tabular}

Source: IDCOL (2019)

Table 3

Installation Projection of SIPs

\begin{tabular}{cc} 
Year & No. of Solar Irrigation Pump (SIPs) \\
\hline 2013 & 09 \\
2014 & 80 \\
2015 & 300 \\
2016 & 450 \\
2017 & 661 \\
2018 & 1013 \\
2019 & 1519 \\
2020 & 2278 \\
2021 & 3417 \\
2022 & 5126 \\
2023 & 7689 \\
2024 & 11533 \\
2025 & 15925 \\
Total & $\mathbf{5 0 0 0 0}$ \\
$\mathbf{2 0 2 7}$ & $\mathbf{1 0 0 0 0}$ (Revised target) \\
\hline
\end{tabular}




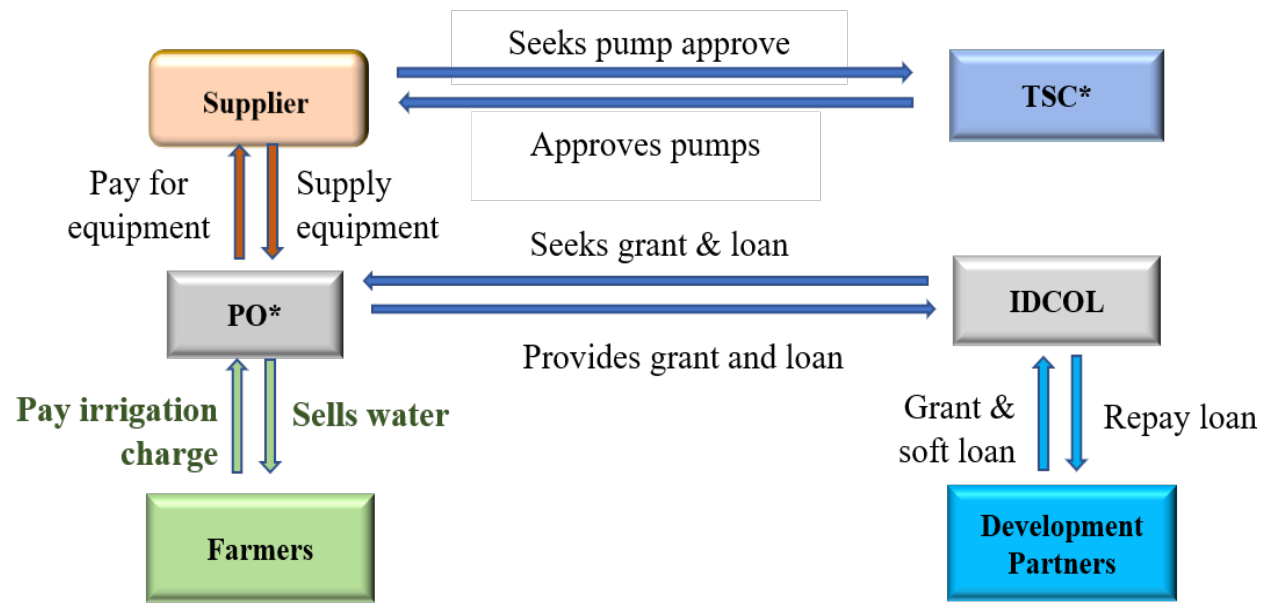

Fig. 2 Fees for Service Model of SIP (adopted from Rahman, 2015)

*TSC: Technical Standards Committee of World Bank. PO*= Partner Organization

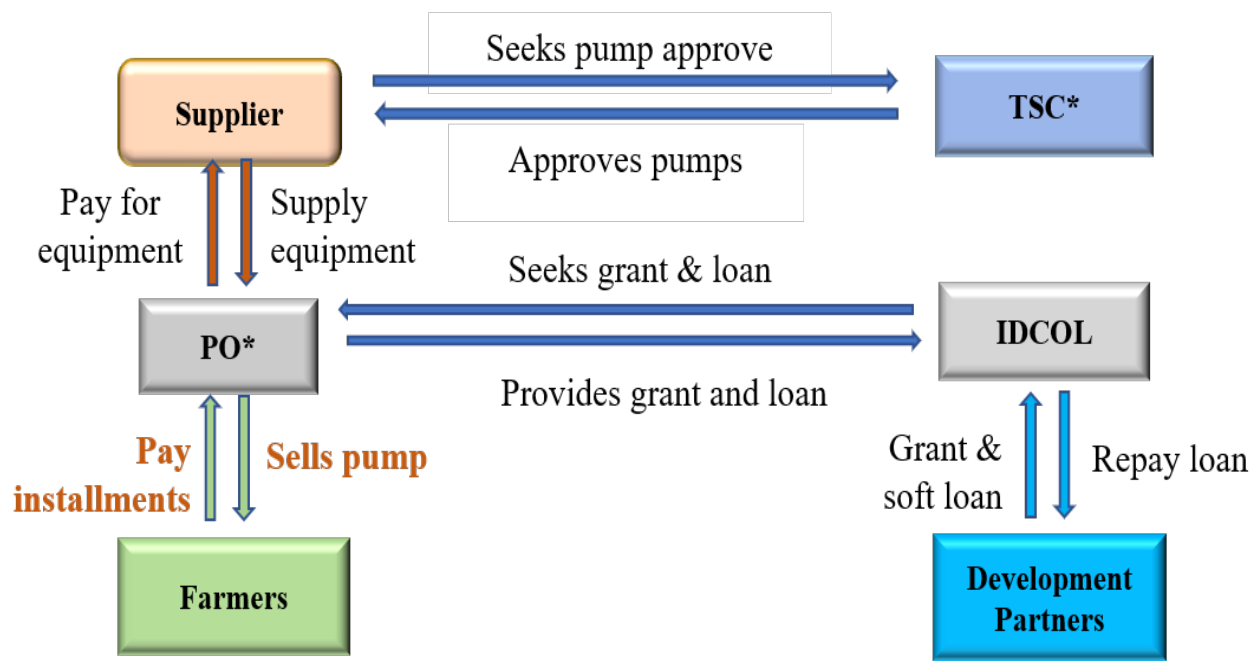

Fig. 3 Fees for Ownership Model of SIP (adopted from Rahman, 2015)

*TSC: Technical Standards Committee of World Bank. PO*= Partner Organization

Table 4

Financing Structure of SIP

\begin{tabular}{lc} 
Particulars & Percentage \\
\hline Grant & $40 \%$ \\
Debt & $40 \%$ \\
Equity (Down payment) & $20 \%$ \\
Total & $\mathbf{1 0 0 \%}$ \\
\hline Source: (Rahman, 2015)
\end{tabular}

Source: (Rahman, 2015)

\subsubsection{Fees for Ownership Model}

The ownership model is almost the same as the service model; POs sell the pump to farmers on cash or credit instead of selling irrigation water to them. Thus, the farmers pay instalments rather than paying irrigation charges to POs for purchasing the SIP. Other functions of the model remain unchanged. The SIP capacity in the ownership model is lower than the service model. IDCOL has not yet launched this model at the field level. Figure 3 illustrates the model. 


\subsection{Financing Structure of Solar Irrigation Pump (SIP)}

IDCOL provided $40 \%$ subsidy and $40 \%$ soft loan of the SIP's total price to install it at the intervention areas. Thus, the grant: debt: equity ratio was equal to 40: 40: 20 percent of the SIP's total price. The owner invested $20 \%$ of the SIP's price as a down payment for installing a SIP (Rahman, 2015). However, IDCOL recently modified the financing structure as grant: debt: equity equal to 50: 35 : 15 per cent of the SIP's total price (Haque, 2018). Table 4 shows the financing structure for the SIPs' installation followed by IDCOL.

\section{Methodology}

This study investigated 14 SIPs from Birganj and Badarganj Upazilas of northern Bangladesh's Dinajpur and Rangpur districts. The highest (185) and the 2nd highest (170) number of SIPs have been installed in Birganj and Badarganj Upazila, respectively (IDCOL, 2019). More SIPs have been installed in these Upazilas for high cropping intensity, Boro cultivation, and grid connectivity shortage. For this reason, these two Upazilas were selected for the study. The 14 SIPs are categorized into four groups to analyze the pumps' economic feasibility. These are large pumps without and with additional use, medium pumps, and small pumps. According to the IDCOL's dissemination models, the medium and large SIPs are designed for the 'fees for service models', and small SIP is designed for the 'fees for ownership model'. Several partner organizations (POs) such as Gazi, Solargao, and Gram installed large and medium SIPs in the visited areas. IDCOL has not yet launched the small SIP for the farmers' consumption. Hence, the 'fees for ownership model' is not yet introduced at the field level. However, few farmers install and operate small SIPs personally in the surveyed areas. To include all categories, we have collected information from the users of 5 large SIPs without any additional use, 2 large SIPs with additional use, 5 medium SIPs, and 2 small SIPs. Secondary information about the SIPs' installation cost has also been collected from IDCOL, SREDA, and PO. After collecting the data, the standard financial and net environmental benefit analysis has been carried out in this study.

\subsection{Financial analysis of different SIPs}

In this study, the standard methods of financial analysis such as a) Net Present Value (NPV), b) Simple Pay Back Period (PBP), and c) Internal Rate of Return (IRR) have been calculated to determine the financial feasibility of different SIPs in the study areas. NPV and IRR are measured for 20 years as the solar panel's warranty period is 20 years. The methods are as follows:

\subsubsection{Net Present Value (NPV)}

NPV is the difference between the present values (PVs) of the total cash inflows (benefits) and the cash outflows (costs). If all future cash flows are incoming and the only cash outflow is the purchase price (PP), the NPV is simply the difference between the present value of future cash inflows and the purchase price (Eq 1) (Chakrabarty \& Islam, 2011).

$$
N P V=\sum_{t=1}^{T} \frac{C F_{t}}{(1+d)^{t}}-P P
$$

Where: $\mathrm{CF}=$ Cashflow; $\mathrm{PP}=$ Purchase price, $\mathrm{t}=$ Period of cash flows, $d=$ Discount rate, $\mathrm{T}=20$

NPVs have been calculated at the discount rates of $6 \%$, $9 \%$, and $12 \%$, which symbolize typical bank interest rates. Thus, we can compare the gains between buying a SIP by money and saving the same amount of money in a scheduled bank.

\subsubsection{Payback Period (PBP)}

The payback period (Eq 2) refers to the period required to return or repay the original investment (Chakrabarty \& Islam, 2011). For example, a $\$ 3000$ investment, returning $\$ 600$ per year, will have a payback period of five years.

$$
P B P=\frac{I I}{N C I / Y}
$$

Where: II= Initial Investment, NCI/Y= Net cash inflow per year

\subsubsection{Internal Rate of Return (IRR)}

The internal rate of return (IRR) is the annualized effective compounded return rate earned on the invested capital. IRR is the discount rate of interest that makes the net present value equal to zero. If the IRR becomes $15 \%$, buying a SIP brings enough revenue in 20 years to pay its cost and grants a return of $15 \%$ on the invested capital. Therefore, in this case, borrowing the required capital at less than $15 \%$ interest rate and finance it for buying a SIP would be a profitable investment (Chakrabarty \& Islam, 2011).

Formula of IRR:

$$
\begin{gathered}
0=C F_{0}+\frac{C F_{1}}{(1+I R R)}+\frac{C F_{2}}{(1+I R R)^{2}}+\ldots+\frac{C F_{n}}{(1+I R R)^{n}} \\
0=N P V=\sum_{n=0}^{N} \frac{C F_{n}}{(1+I R R)^{n}}
\end{gathered}
$$

Where:

$$
\begin{aligned}
\mathrm{CF}_{1}, \mathrm{CF}_{2}, \ldots \mathrm{CF}_{\mathrm{n}}= & \text { Cash flows } \\
\mathrm{n}= & \text { Each period } \\
\mathrm{N}= & \text { Holding period }(20 \text { years }) \\
\mathrm{NPV}= & \text { Net present value } \\
\mathrm{IRR}= & \text { Internal rate of return }
\end{aligned}
$$

\subsection{Environmental Benefit of SIP}

The environmental benefits, and the environmental costs of SIPs, have been calculated in the study to measure SIPs' net environmental benefit. At first, according to the Intergovernmental Panel on Climate Change (IPCC) guidance, the most common methodological approach to calculate the environmental benefit of any investment is to combine information about human activities (called 
activity data or $\mathrm{AD}$ ) with coefficients that quantify the emissions per unit activity (Roberta, 2006). These are called emission factors (EF). The basic equation is stated by equation 4 :

$$
\text { Emissions }=\mathrm{AD} \times \mathrm{EF}
$$

Here, the activity data $(\mathrm{AD})$ is the substituted amount of diesel by SIP, and emission factors (EF) are the diesel's carbon content. $\mathrm{CO}_{2}$ emission is estimated by multiplying the total amount of fuels combusted and the fuels' average carbon content. Thus, the $\mathrm{CO}_{2}$ emission reduction is the multiplication of the total substituted diesel by the SIP and per unit diesel's $\mathrm{CO}_{2}$ generation. The reduction indicates the environmental benefit of SIP (EBSIP). The EBSIP is calculated based on equation 5 :

$$
\mathrm{EBSIP}=\mathrm{TDU} \times 2.8 \mathrm{~kg}
$$

TDU $=$ Total diesel used in 20 years in liter (1-liter diesel $=2.8 \mathrm{~kg} \mathrm{CO} 2)(\mathrm{Dev}, 2014)$

The EBSIP can be expressed in monetary terms as follows:

$$
\text { EBSIP in Monetary terms }=\frac{\text { EBSIP }}{1000} \times \mathrm{CRCO}_{2}
$$

Here, EBSIP is Environmental benefit of a SIP and $\mathrm{CRCO}_{2}$ is the cost of removal of $\mathrm{CO}_{2}$ per ton (100 USD).

Keith et al. calculated the cost of removing one ton of $\mathrm{CO}_{2}$ from the atmosphere is about 100 USD in their study (Keith et al., 2018). On the other hand, according to the study of Krauter and Ruther, the corresponding emission of $\mathrm{CO}_{2}$ for the manufacturing of each $\mathrm{kWp}$ of PV panels by polycrystalline silicon is $170 \mathrm{KgCO}_{2} / \mathrm{kWp}$ (Krauter \& Rüther, 2004). This information has been used to calculate a SIP's environmental costs. Finally, a SIPs' net environmental benefit has been calculated by subtracting the benefit and cost.

\section{Basic information of visited SIPs}

The visited SIPs have been categorized into four groups according to their capacities and functions, such as:

1. Large SIP without additional use

2. Large SIP with additional use

3. Medium SIP

4. Small SIP
This categorization helped analyze, explain, and compare the economic feasibility of different SIPs. Some of the large SIPs have additional use options. Thus, a large SIP with an additional application is also considered in this study.

The large and medium SIPs are deployed under the 'fees for service model'. After installation, the partner organizations (POs) own the large and medium SIPs, and the farmers would possess the small SIPs. POs appoint an operator for each large and medium SIP to operate them and collect the irrigation fees from farmers. The operator's compensation is Tk.3000 per month as salary and 20\% of the total collected irrigation fees as commission per year. Moreover, small SIPs are more suitable for the 'fees for ownership model'.

The information about cash outflows and cash inflows of SIPs has been collected from the installers and farmers. The cash outflows and inflows are the main components for the financial analysis of the pumps. Other basic information of different SIPs like the panel and pump capacity, required land to install, cultivable crops under the pump's coverage, and so on have been discussed in the next subsections.

\subsection{Basic Information of a Large SIP without Additional Use}

POs installed large SIPs under the 'fees for service model' at the visited areas. They received $40 \%$ grant and $40 \%$ soft loan from IDCOL and paid $20 \%$ of the pump's total price as down payment. Thus, the total installation cost of the large SIP with $40 \%$ grant becomes about Tk.2793840. A large SIP with $30 \mathrm{kWp}$ solar panels (120 panels with $250 \mathrm{~W}$ each) and $15 \mathrm{~kW}$ pump can deliver about 1800000 litre water per day and can provide irrigation facility to 100 bigha land for Boro cultivation and more than 120 bigha land for other crops cultivation. The irrigation charge for Boro cultivation is Tk.3500 per bigha for one season and for other crops is Tk.250 per bigha for one irrigation. The pump runs on average 200 days a year and remains unused on the other days of the year. Frequently, this type of large SIP without additional use needs 20 decimal land to install. Table 5 provides the basic information of a large SIP. The main cash outflows are the installation and operating costs, and the main cash inflow is the irrigation fees for the large SIP without any additional use.

Table 5

Basic Information of a Large SIP without Additional Use

\begin{aligned} \multicolumn{1}{c}{ Subject } & \multicolumn{1}{c}{ Information } \\ \hline Panel capacity: & $30 \mathrm{kWp}(250 \mathrm{~W} \times 120$ panels $) \\$ Pump capacity: & $15 \mathrm{~kW}(7.5 \mathrm{~kW} \times 2$ Pumps) \\ Water flow: & $1800 \mathrm{~m} / \mathrm{d} / \mathrm{day}$ or 1800000 Liter/day \\ Offers: & Irrigation facility to 100 bigha land for Boro and 120 bighas for other crops cultivation \\ Purchasing pattern: & $40 \%$ grant, $40 \%$ loan and $20 \%$ down payment \\ Total cost: & Tk.2793840 (after receiving $40 \%$ grant) \\ Irrigation Charge: & Tk.3500/bigha/season for Boro and Tk.250/bigha/irrigation for other crops. \\ Installed by: & Solargao/ Gazi/ Gram \\ Facility: & Irrigation only \\ Number of farmers: & 30 \\ Required land: & 20 decimal \\ Operating days: & $200 /$ year \\ Cultivable crops: & Amon, Boro, mustard, potato, corn, etc. \end{aligned}

Source: field survey 2019; (1 bigha=50 decimal) 
Table 6

Basic Information of a Large SIP with Additional Use

\begin{aligned} \hline Subject & \\ \hline Panel capacity: & $30 \mathrm{kWp}(250 \mathrm{~W} \times 120 \mathrm{panels}) \\$ Pump capacity: & $15 \mathrm{~kW}(7.5 \mathrm{~kW} \times 2 \mathrm{Pumps}) \\$ Water flow: & $1800 \mathrm{~m}^{3} / \mathrm{day}$ or $1800000 \mathrm{Liter} / \mathrm{day} \\$ Offers: & Irrigation facility to $100 \mathrm{bigha}$ land for Boro and 120 bighas for other crops cultivations \\ Purchasing pattern: & $40 \%$ grant, $40 \%$ loan and $20 \%$ down payment \\ Total cost: & Tk.2903840 (after receiving $40 \%$ grant) \\ Irrigation Charge: & Tk.3500/bigha/season for Boro and Tk.250/bigha/irrigation for other crops. \\ Installed by: & Solargao/ Gazi/ Gram \\ Additional use: & Paddy husking at the rate of Tk.15/Maund. (1 Maund=40kg) \\ Facility: & Irrigation and husking \\ Number of farmers: & 30 \\ Required land: & 30 decimal \\ Cultivable crops: & Amon, Boro, mustard, potato, corn, etc. \end{aligned}
Source: field survey 2019; (1 bigha $=50$ decimal)

\subsection{Basic Information of a Large SIP with Additional Use}

POs install and maintain large SIPs with additional use at the field level. It is operated under the 'fees for service model.' Additional provisions like husking and grinding facilities have been found with the large SIP in the visited area. During the interval of two harvests or in the rainy season, when irrigation is unnecessary, or, one out of two pumps is sufficient to meet the irrigation requirement, the solar energy is used for husking or grinding purposes. The husking machine's power is $10 \mathrm{HP}$ or $7.5 \mathrm{~kW}$, equal to each pump's power. Thus, one pump and the husking machine can run simultaneously by solar electricity. After receiving 40\% grant from IDCOL, the SIP's price with the paddy husking facilities became Tk.2903840. About 30 decimal land is necessary to install this pump with the additional use. Table 6 presents the necessary information of a large SIP with a husking machine.

The main cash outflows are the installation and operating costs, and the cash inflows are the irrigation and paddy husking fees for the SIP with additional use.

\subsection{Basic Information of a Medium SIP}

POs also install and maintain medium SIPs and operate them under the 'fees for service model.' A medium SIP with $15 \mathrm{kWp}$ solar panels (60 panels with $250 \mathrm{~W}$ each) and a $7.5 \mathrm{~kW}$ pump delivers about 1100000 litre water per day. It can provide irrigation facility to 50 bigha land for Boro and more than 70 bigha land for other crops cultivation. IDCOL offered $40 \%$ grant, $40 \%$ soft loan, and PO paid $20 \%$ of the pump's total price as a down payment. Thus, the total installation cost of the medium SIP after receiving 40\% grant became about Tk.1881948. The pump's irrigation charge for Boro cultivation is Tk.3500 per bigha for one season. For the other crop, the charge is Tk.250 per bigha per irrigation. About 20 farmers are receiving irrigation services from the SIP. The pump is operated on an average of 200 days and remained unused on the other days of the year. On average, 10 decimal land is necessary to install a medium SIP. Table 7 provides a summary of the basic information of a medium SIP. The main cash outflows for a medium SIP are the installation and operating costs, and the only cash inflow is the irrigation fees.

Table 7

Basic Information of a Medium SIP

\begin{aligned} \hline Subject & \multicolumn{1}{c}{ Information } \\ \hline Panel capacity: & $15 \mathrm{kWp}(250 \mathrm{~W} \times 60$ panels $) \\$ Pump capacity: & $7.5 \mathrm{~kW}(3.75 \times 2$ Pumps) \\ Water flow: & $1100 \mathrm{~m} 3 /$ day or 1100000 Liter/day \\ Offers: & Irrigation facility to 50 bigha for Boro and 70 bigha for other crops cultivation \\ Purchasing pattern: & $40 \%$ grant, $40 \%$ loan and $20 \%$ down payment \\ Total cost: & Tk.1881948 (after receiving $40 \%$ grant) \\ Irrigation Charge: & Tk.3500/bigha/season for Boro and Tk.250/bigha/irrigation for other crops. \\ Installed by: & Solargao/ Gazi/ Gram \\ Facility: & Irrigation only \\ Number of farmers: & 20 \\ Required land: & 10 decimal \\ Operating days: & $200 /$ year \\ Cultivable crops: & Amon, Boro, mustard, potato, corn, etc. \end{aligned}

Source: field survey 2019; (1 bigha=50 decimal) 
Table 8

Basic Information of a Small SIP

\begin{aligned} \hline Subject & \multicolumn{1}{c}{ Information } \\ \hline Panel capacity: & $4 \mathrm{kWp}(250 \mathrm{~W} \times 16$ panels) \\ Pump capacity: & $2.5 \mathrm{~kW} \\$ Water flow: & $350 \mathrm{~m} / \mathrm{day}$ or 350000 Liter/day \\ Offers: & Irrigation facility to 16 bigha land for Boro and 30 bigha land for other crops cultivation. \\ Purchasing pattern: & $40 \%$ grant, $40 \%$ loan and $20 \%$ down payment \\ Total cost: & Tk.406128 (after receiving $40 \%$ grant) \\ Irrigation Charge: & Tk.3500/bigha/season for Boro and Tk.250/bigha/irrigation for other crops. \\ Installed by: & Solargao/ Gazi/ Gram \\ Facility: & Irrigation only \\ Number of farmers: & 05 \\ Required land: & $2-3$ decimal \\ Operating days: & $200 /$ year \\ Cultivable crops: & Amon, Boro, mustard, potato, corn, etc. \end{aligned}

Source: field survey 2019; ( 1 bigha $=50$ decimal)

\subsection{Basic Information of a Small SIP}

Small SIP's financial structure is designed for the 'fees for ownership model.' IDCOL would support POs to install the pump for the farmer's consumption. A typical small SIP with $4 \mathrm{kWp}$ solar panels and $2.5 \mathrm{~kW}$ pump can deliver about 350000 litre water per day (IDCOL, 2019). It can provide irrigation facility to 16 bigha land for Boro cultivation and more than 30 bigha land for other crops cultivation. IDCOL offered $40 \%$ grant, $40 \%$ soft loan, and the consumer has to pay $20 \%$ of the pump's price as down payment. Thus, the small SIP's total cost after receiving $40 \%$ grant becomes about Tk.406128. The basic information of a small SIP has been given in Table 8 .

After purchasing, the farmer can save his irrigation cost and rent out the unused irrigation facility to the adjacent farmers. Thus, he can earn from the irrigation charge at the mentioned rate in Table 8 from the investment. Only 2-3 decimal land is necessary for the installation of a small SIP. The main cash outflow of a small personal SIP is the installation cost, and the cash inflow is the irrigation fees.

\section{Discussion of Results}

\subsection{Financial Indicators of Different SIPs}

This study utilized the information about cash outflows and cash inflows to compute the financial indicators such as NPV, PBP, and IRR of SIPs. The indicators help to realize which SIP is the most feasible option for investment. NPVs have been calculated at the discount rates of $6 \%, 9 \%$, and $12 \%$, which symbolize typical bank interest rates. Therefore, comparing the gains of installing a SIP and saving the installation money in a scheduled bank can be possible. IRR helps show the actual return rate at which the net present value of an investment becomes zero. The PBP shows the time required for covering the project's total cost, and after the period, the project starts to earn a profit. Table 9 demonstrates the results of all financial indicators of large, medium, and small SIPs. The overview of the financial analysis of all SIPs is also shown in Fig. 4.

\subsubsection{Large Solar Irrigation Pump (SIP)}

The large SIPs are moderately profitable without and with additional use (1a, $1 \mathrm{~b}$ in Table 9). The NPVs at $6 \%$ and $9 \%$ interest rates are positive, but the values are negative at $12 \%$ interest rate. NPVs have increased by more than Tk.100000 due to the introduction of additional use (husking service) of solar energy. The IRRs are about $10 \%$ and $10.50 \%$ for the SIPs without and with additional use. Moreover, the simple PBP of the large SIP with and without additional use is about 7.82 and 8.10 years, respectively. Therefore, the large SIP's financial outcome with additional use seems more viable than without any additional use. A higher financial gain is possible by introducing more additional uses such as delivering water for fish cultivation, households, and hotel usages, supplying excess solar electricity to the national grid and so on.

Table 9

The Outcomes of the Financial Analysis of Different SIPs

\begin{tabular}{lccccc}
\hline Solar irrigation pump (SIP) & NPV (6\%) & NPV (9\%) & NPV (12\%) & IRR & $\begin{array}{c}\text { Payback period } \\
\text { (PBP) in years }\end{array}$ \\
\hline 1. a) Large SIP without additional use & 990167 & 224460 & -316227 & 10 & 8.10 \\
b) Large SIP with additional use & 1135324 & 320069 & -255617 & 10.50 & 7.82 \\
2. Medium SIP & -109868 & -469166 & -722579 & 5.30 & 12.91 \\
3. Small SIP & 555470 & 358393 & 219356 & 20.10 & 4.84 \\
\hline
\end{tabular}

Source: Author's calculation based on field survey data, 2019 


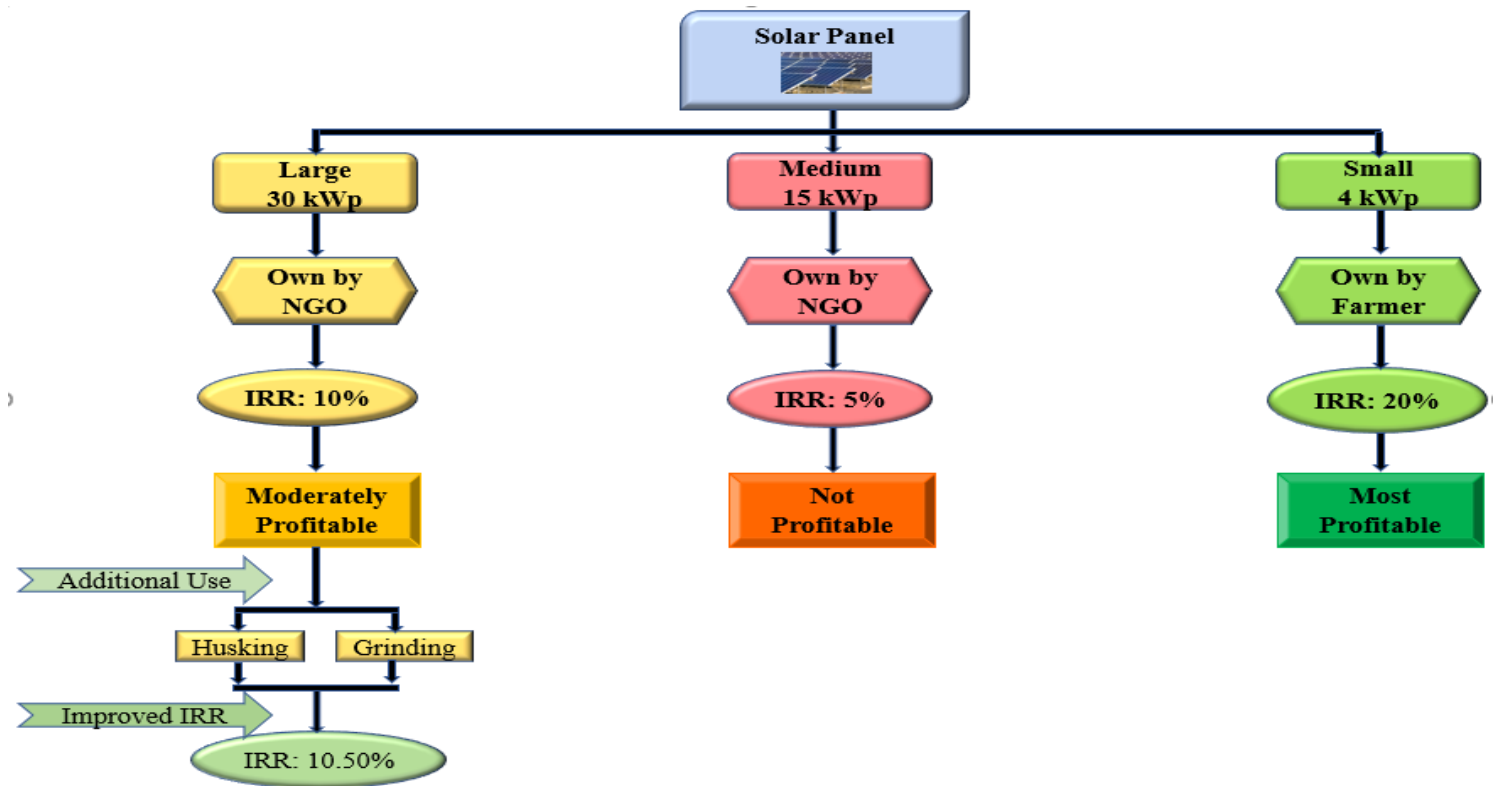

Fig. 4 An overview of the financial analysis of SIPs conducted in the study

\subsubsection{Medium Solar Irrigation Pump (SIP)}

The financial indicators of a medium SIP seem unattractive with negative NPVs at all interest rates, less than $6 \%$ IRR, and more than 12 years PBP. The leading causes of the pump's unattractive financial indicators are the high installation cost, operator's salary, and $20 \%$ commission on collected irrigation fees. Also, no additional use of this pump was found in the survey areas. Hence, installing a medium SIP would not be a viable option for investment.

Though the financial analysis indicates that installing and operating a medium SIP is not profitable, POs have installed 186 medium SIPs in Dinajpur and Rangpur districts (IDCOL, 2019). They operate 186 medium SIPs as 93 pairs of them. A pair of medium SIPs' irrigation coverage, total panel, and pump capacity is the same as a large SIP. However, the installation costs of a medium and a large SIP are around Tk.3000000 and Tk.5000000, respectively (IDCOL 2019). So, a pair of medium SIPs' installation costs are almost Tk.6000000, and a large SIP's cost is around Tk.5000000. The difference in the installation cost of 2 medium and 1 large SIP is about Tk.1000000. Therefore, the installers (POs) received about Tk.400000 as a grant (40\% of total cost) and another Tk.400000 as a soft loan (40\% of total cost) for installing a pair of medium SIPs. These benefits from grants and loans may incentivize POs to install medium SIPs, which has been found the least viable option for investment.

\subsubsection{Small Solar Irrigation Pump (SIP)}

The small SIP's financial indicators are the best among all types of SIPs. Its NPVs at all three interest rates are positive, the PBP is less than 5 years, and the IRR is more than $20 \%$. Therefore, the indicators of a small SIP are found most attractive compare to other SIPs. This finding is in line with the findings obtained by Surendra and
Subbaraman findings. They found that small solar pumps for irrigation are most suitable for India (Surendra \& Subbaraman, 2002). So, the 'fees for ownership model' would be more feasible than the 'fees for service model' in Bangladesh.

Moreover, the total installation cost of a small SIP (4kWp) offers by IDCOL is Tk.676880, which will be about Tk.406128 after receiving 40\% subsidy. It still looks expensive for the farmer to afford it. Nevertheless, it would be possible to reduce the small SIP's installation cost. As some provisions like underground pipeline, brickbuilt room is not essential for small SIP. Besides, its total price can be reduced by decreasing panel and pump capacity. For example, a small SIP with $2.50 \mathrm{kWp}$ panels and $1.2 \mathrm{~kW}$ pump can provide irrigation facilities to 10 bigha land for Boro cultivation. Thus, by revising the provision and capacity, small SIP's market price can be reduced to around Tk.200000. After 40\% subsidy on this price, it would be an attractive investment option for farmers.

\subsection{Environmental Benefit of Solar Irrigation Pump (SIP)}

SIPs have some direct potential to reduce greenhouse gas (GHG) emissions from irrigation activities by replacing fossil fuels with solar energy. We found from the field survey that, on average, 37.5 litre and 3 litre diesel is necessary for Boro and other crops cultivation in one bigha land in a season. At present, SIPs mainly substitute diesel with solar energy in the country. Thus, diesel consumption and $\mathrm{CO}_{2}$ emission from diesel combustion are reducing substantially due to the introduction of SIP. In this study environmental benefit of SIP is estimated using the information that 1 litre diesel produces $2.8 \mathrm{~kg} \mathrm{CO}_{2}$, and the cost of removing 1 ton $\mathrm{CO}_{2}$ from the atmosphere is 100 USD. The calculated total environmental benefits of the large, medium and small SIPs in 20 years are Tk.2002560, Tk.1028160, and Tk.349440, respectively (Table 10). 
Table 10

Environmental Benefit of Large, Medium and Small SIPs in 20 Years

\begin{tabular}{lcccc}
\hline Pumps & $\begin{array}{c}\text { Coverage for Boro } \\
\text { (bigha) }\end{array}$ & $\begin{array}{c}\text { Required diesel (Liter) } \\
\mathbf{C O}_{2} \text { emission } \\
\text { reduction (Ton) }\end{array}$ & $\begin{array}{c}\text { Benefit from CO } \mathbf{C O}_{2} \text { reduction } \\
\text { (Tk) }\end{array}$ \\
\hline Large & 100 & 89400 & 250.32 & 2002560 \\
Medium & 50 & 45900 & 128.52 & 1028160 \\
Small & 16 & 15600 & 43.68 & 349440 \\
\hline
\end{tabular}

Author's calculation based on field survey data, 2019; 1 bigha $=50$ decimal, 1 USD $=T k .80$

Table 11

Subsidy and Environmental Benefit of Different Solar Irrigation Pumps (Tk)

\begin{tabular}{lccccccc}
\multicolumn{1}{c}{ SIP } & $\begin{array}{c}\text { Panel } \\
\text { capacity } \\
\mathbf{( k W p )}\end{array}$ & $\begin{array}{c}\text { Price } \\
\text { (Without } \\
\text { subsidy) }\end{array}$ & $\begin{array}{c}\text { Price (With } \\
\text { subsidy) }\end{array}$ & $\begin{array}{c}\text { Subsidy } \\
\mathbf{( 4 0 \% \text { of }} \\
\text { price) }\end{array}$ & $\begin{array}{c}\text { Subsidy/ } \\
\mathbf{k W p}\end{array}$ & $\begin{array}{c}\text { Net Env. } \\
\text { benefit in 20 } \\
\text { years }\end{array}$ & $\begin{array}{c}\text { Net Env. } \\
\text { benefit /kWp }\end{array}$ \\
\hline Large & 30 & 4656400 & 2793840 & 1862560 & 62085 & 1961760 & 65392 \\
Medium & 15 & 3136580 & 1881948 & 1254632 & 83642 & 1007760 & 67184 \\
Small & 4 & 676880 & 406128 & 270752 & 67688 & 344000 & 86000 \\
\hline
\end{tabular}

Source: Author's calculation based on field survey data, 2019; $P O=$ Partner Organization, $1 U S D=T k .80$

On the other hand, the SIP's main environmental cost is the emitted $\mathrm{CO}_{2}$ from solar PV panels' production process. Generally, the emitted amount of $\mathrm{CO}_{2}$ is $170 \mathrm{Kg} / \mathrm{kWp}$ in manufacturing polycrystalline silicon PV panels. Thus, the large, medium and small SIPs produce 5.1 ton, 2.55 ton, and 0.68 ton $\mathrm{CO}_{2}$, and the removal cost of these amounts of $\mathrm{CO}_{2}$ is about Tk.40800, Tk.20400, Tk.5440, respectively. Therefore, the tentative net environmental gains of large, medium and small SIPs are Tk.1961760, Tk.1007760, and Tk.344000, respectively. Ould-Amrouche et al. (2010), Nikzad et al. (2019), Rathore et al. (2018), and Hossain et al. (2015) also mentioned that SIPs significantly reduce $\mathrm{CO}_{2}$ emissions by replacing conventional irrigation pumps (CIPs). This study also supported the claim of the environmental benefit of SIP and tried to measure the benefit in monetary terms. Finally, the SIP's environmental benefit has been calculated by considering only the substituted diesel by solar energy. If the reduction of sound pollution and water contamination with diesel were considered, the SIP's actual gain would be more than the calculated benefit.

\subsection{Comparison of the subsidy and environmental benefit of solar irrigation pump (SIP)}

The comparison between the given subsidies and the net environmental benefits of SIPs is given in Table 11. Table 11 shows that the given subsidy (40\% of SIP's total price) almost equals the pumps' net environmental benefit in 20 years. The net environmental benefit per $\mathrm{kWp}$ of the large and medium SIPs is almost equal at around Tk.65000. However, the small SIP's net environmental benefit per $\mathrm{kWp}$ is more than Tk.85000. So, the small SIP's net environmental benefit per $\mathrm{kWp}$ has become the highest.

\section{Conclusion}

Irrigation is vital for agriculture-based countries like Bangladesh to ensure their food security. The requirement for irrigation rises over the years, mainly due to the increase of High Yielding Variety (HYV) use, the decline of the water table, reduction of surface water sources, increase of cropping areas, and climatic volatility. In this regard, solar irrigation would be a reliable source of irrigation. Therefore, this study aims to conceive SIPs' economic feasibility in northern Bangladesh by conducting standard financial and net environmental benefit analyses.

The small SIP is economically the most feasible option for investment. Then, the large SIP is a moderately profitable option for investment, and it can be improved by introducing additional uses of solar energy. Next, the financial indicators are not viable in the case of medium SIPs. Therefore, the 'fees for ownership model' is found more profitable than the 'fees for service model' of SIPs. 'Fees for ownership model' is also more effective in bringing the benefits of given subsidies and soft loans to the farmers.

Moreover, the SIP's net environmental benefit is almost equal to the given subsidy to install it. Thus, the provided grant ( $40 \%$ of the total price) has been justified for this investment, and the authority should continue providing subsidies on its installation. Besides, the net environmental benefit per $\mathrm{kWp}$ is highest for the small SIP. Therefore, the financial indicators and the environmental benefit reveal that small SIP is the most profitable investment option. The government should launch the 'fees for ownership models' of SIPs for farmers' personal or group use. The small personal SIPs can ensure its quick dissemination and help increase the country's agricultural production as well as improve the environmental condition.

In the future, the researchers may think about highly subsidized investment, especially for renewable energy technology adoption. For example, from this study, the government provided $40 \%$ subsidy and $40 \%$ soft loan on the total price for installing the SIP. Government cannot take collateral from the farmers for the $40 \%$ loan. However, the NGOs ensure repayment of the loan, and IDCOL provides them grants and soft loans to install, operate and own the SIPs. Therefore, it creates a chance for the NGOs to get undesirable benefits from the highly subsidized, overvalued project. On the other hand, if the government provides an equipment-based subsidy, for example, subsidy on panel's price may facilitate all the consumers. However, the targeted group may not receive the full benefit of it. Thus, an acceptable mechanism to get 
back the loan or help the targeted group directly would ensure quick dissemination of the renewable energy-run machinery.

\section{Acknowledgement}

We want to thank the editors and two anonymous reviewers for their valuable comments and opinions. We are also grateful to Zinat Tasneem, Department of Mechatronics Engineering, Rajshahi University of Engineering and Technology, for her valuable assistance.

\section{References}

Agrawal, S., \& Jain, A. (2019). Sustainable deployment of solar irrigation pumps: Key determinants and strategies. Wiley Interdisciplinary Reviews: Energy and Environment, 8(2), 1-14. https://doi.org/10.1002/wene.325

Ali, B. (2018). Comparative assessment of the feasibility for solar irrigation pumps in Sudan. Renewable and Sustainable Energy Reviews, 81, 413-420. https://doi.org/10.1016/j.rser.2017.08.008

Allen, S. (2011). Carbon Footprint of Electricity Generation. Postnote Update, 383, 1-4.

Al-Masum, R. F., Ashraf, M. A., \& Islam, M. T. (2017). Environmental Contamination By CO2 Emission Through Irrigation Pump. Bangladesh J. Environ. Sci., 32, 204-207.

BADC. (2020). Organization Wise Summary of Irrigation Equipment Used, Area Irrigated and Benefited Farmers. http://www.badc.gov.bd/ (accessed 10th January 2020).

BBS. (2015). Poulation projection of Bangladesh- Dynamics and Trends. In Statistics and Informatics Division, Government of the People's Republic of Bangladesh (Vol. 53, Issue 9).

BBS. (2018). Yearbook of Agricultural Statistics-2017 (Vol. 29, Issue April). bbs.portal.gov.bd

BBS. (2019). Statistical Yearbook Bangladesh 2019 (Issue May). bbs.portal.gov.bd

BPDB. (2020). Institutional-and-policy-framework - Power Division-Government of the People's Republic of Bangladesh.

https://powerdivision.gov.bd/site/page/957a6271-87524a21-9cb1-02ddd6b58b6f/Institutional-and-policyframework (accessed May 12 2017).

Chakrabarty, S., \& Islam, T. (2011). Financial viability and ecoefficiency of the solar home systems (SHS) in Bangladesh. Energy, 36(8). https://doi.org/10.1016/j.energy.2011.05.016

Dev, J. K. (2014). Assessment of Potential Environmental Benefits of Using Solar Power for Irrigation Pump in Bangladesh [Department of Civil Engineering, BUET]. http://lib.buet.ac.bd:8080/xmlui/handle/123456789/684

Division, Power., Renewable Energy Policy of Bangladesh, Ministry of Power, Energy and Mineral Resources, Government of the People's Republic of Bangladesh http://www.powerdivision.portal.gov.bd (accessed 15 March 2018).

García, M. A., Gallagher, J., McNabola, A., Camacho Poyato, E., Montesinos Barrios, P., \& Rodríguez Díaz, J. A. (2019). Comparing the environmental and economic impacts of onor off-grid solar photovoltaics with traditional energy sources for rural irrigation systems. Renewable Energy, 140, 895-904. https://doi.org/10.1016/j.renene.2019.03.122

Hamidat, A., Benyoucef, B., \& Hartani, T. (2003). Small-scale irrigation with photovoltaic water pumping system in Sahara regions. Renewable Energy, 28(7), 1081-1096. https://doi.org/10.1016/S0960-1481(02)00058-7

Haque, N. (2018). Solar Irrigation in Bangladesh: Opportunities \& Challenges (Issue October). www.idcol.org

Hoque, N., Roy, A., Mohd. Rafiqul Alam Beg, \& Das, B. K. (2016).
Techno-economic evaluation of solar irrigation plants installed in Bangladesh. International Journal of Renewable Energy Development, 5(1), 73-78. https://doi.org/10.14710/ijred.5.1.73-78

Hossain, M. A., Hassan, M. S., Mottalib, M. A., \& Hossain, M. (2015). Feasibility of solar pump for sustainable irrigation in Bangladesh. International Journal of Energy and Environmental Engineering, 6(2), 147-155. https://doi.org/10.1007/s40095-015-0162-4

IDCOL. (2019). Idcol Solar Irrigation Projects. https://idcol.org/home/solar_ir (accessed 20 August 2019).

IDCOL. (2021). Infrastructure Development Company Limited. https://idcol.org/home/solar_ir (accessed 18 January 2021).

Islam, M. R.., \& Beg, M. R. A. (2008). Renewable energy resources and technologies practice in Bangladesh. Renewable and Sustainable Energy Reviews, 12(2), 299-343. https://doi.org/10.1016/j.rser.2006.07.003

Keith, D. W., Holmes, G., St. Angelo, D., \& Heidel, K. (2018). A Process for Capturing CO2 from the Atmosphere. Joule, 2(8), 1573-1594.https://doi.org/10.1016/j.joule.2018.05.006

Kelley, L. C., Gilbertson, E., Sheikh, A., Eppinger, S. D., \& Dubowsky, S. (2010). On the feasibility of solar-powered irrigation. Renewable and Sustainable Energy Reviews, 14(9), https://doi.org/10.1016/j.rser.2010.07.061

Krauter, S., \& Rüther, R. (2004). Considerations for the calculation of greenhouse gas reduction by photovoltaic solar energy. Renewable Energy, 29(3), 345-355. https://doi.org/10.1016/S0960-1481(03)00251-9

Meah, K., Ula, S., \& Barrett, S. (2008). Solar photovoltaic water pumping opportunities and challenges. Renewable and Sustainable Energy Reviews,12(4), 1162-1175. https://doi.org/10.1016/j.rser.2006.10.020

Nikzad, A., Chahartaghi, M., \& Ahmadi, M. H. (2019). Technical, economic, and environmental modeling of solar water pump for irrigation of rice in Mazandaran province in Iran: A case study. Journal of Cleaner Production, 239, 118007. https://doi.org/10.1016/j.jclepro.2019.118007

Ould-amrouche, S., Rekioua, D., \& Hamidat, A. (2010). Modelling photovoltaic water pumping systems and evaluation of their CO2 emissions mitigation potential. Applied Energy, $87(11)$ https://doi.org/10.1016/j.apenergy.2010.05.021

Pande, P. C., Singh, A. K., Ansari, S., Vyas, S. K., \& Dave, B. K. (2003). Design development and testing of a solar PV pump based drip system for orchards. Renewable Energy, 28(3),385-396. https://doi.org/10.1016/S0960-1481(02)00037-X

Purohit, P., \& Kandpal, T. C. (2011). Solar photo water pumping in India : a financial evaluation. Int J Ambient Energy, 26, 37-41. https://doi.org/10.1080/01430750.2005.9674983

Rahman, Farzana, "Idcol Solar Irrigation Projects - Icimod" www.icimod.org/resource/17186 (accessed October 20 2017).

Rathore, P. K. S., Das, S. S., \& Chauhan, D. S. (2018). Perspectives of solar photovoltaic water pumping for irrigation in India. Energy Strategy Reviews, 22, 385-395. https://doi.org/10.1016/j.esr.2018.10.009

Roberta Q., Guidelines for National Greenhouse Gas Inventories,Volume-2, Energy, International Panel on Climate Change, IPCC http://www.ipccnggpip.iges,or.jp/public/2006gl/vol2.html (accessed 10th May 2018).

Sass, J., \& Hahn, A. (2020). Solar Powered Irrigation Systems (SPIS) Technology, Economy, Impacts.

SREDA. (2020). Sustainable and Renewable Energy Development Authority, "Electricity Installed from Renewable Energy", Power Division, Ministry of Power, Energy and Mineral Resources, Government of the Peoples Republic of Bangladesh. http://www.sreda.gov.bd/index.php/re_master_pdf (accessed 15th February 2019). 
Surendra, T. S., \& Subbaraman, S. V. V. (2002, May). Solar PV water pumping comes of age in India. In Conference Record of the Twenty-Ninth IEEE Photovoltaic Specialists Conference, 2002. (pp. 1485-1488). IEEE.

Tanvir, R. U., Shahadat, M. R. B., Ghosh, M., \& Khan, M. (2017) Prospects and Utilization of Renewable Energy in Bangladesh: A Review Article. International Journal of Scientific \& Engineering Research, 8(4).

VEIPL. (2018). Vatio Energy India Private Limited. http://vatioenergy.com/solarwaterpumping.html (accessed 22 October 2018).

World bank. (2019). Population, total - Bangladesh | Data. https://data.worldbank.org/indicator/SP.POP.TOTL?end= 2019\&locations $=$ BD\&start=1960. (accessed 21 July 2019).

(C) 2022. The Authors. This article is an open access article distributed under the terms and conditions of the Creative Commons Attribution-Share Alike 4.0 (CC BY-SA) International License (http://creativecommons.org/licenses/by-sa/4.0/) 